\title{
ВЗАИМНЫЕ ПРАВА И ОБЯЗАННОСТИ ПРЕДСТАВИТЕЛЯ И ТРЕТЬИХ ЛИЦ, А ТАКЖЕ ПРЕДСТАВЛЯЕМОГО ЛИЦА И ТРЕТЬИХ ЛИЦ В РАМКАХ ПРАВООТНОШЕНИЯ ПРЕДСТАВИТЕЛЬСТВА ПО РОССИЙСКОМУ И АМЕРИКАНСКОМУ ПРАВУ
}

\begin{abstract}
Аннотация: Статья посвящена вопросу взаимных прав и обязанностей представителя и третьих лии, а также представляемого лица и третьих лиц в рамках правоотношения представительства по российскому и американскому праву. Проводиться сравнительный анализ правоотношения представительства в российском и американском праве на примере правового регулирования взаимных прав основных участников правоотношения с третьими лицами. Исследуются такие вопросы как: возникновение взаимных прав и обязанностей у представляемого лица и третьих лиц; информирование третьих лиц представляемым лицом; право (обязанность) представителя вступать в отношения с третьими лицами и круг его полномочий; ограничение прав представителя на вступление в отношения с третьими лицами с иелью осуществления действий в их интересах. В статье используются классические для юридической науки методы исследования. Основное место уделено сравнительно-правовому методу исследования. Утверждается, что правоотношения представительства, а также их правовое регулирование в российском и американском праве довольно схожи. Это подтверждается возможностью выделения общих для российского и американского права принцииов и элементов данного правоотношения, основным их которых являются права и обязанности третьих лиц при их взаимодействии с основными участниками правоотношения представительства.
\end{abstract}

Ключевые слова: Юриспруденция, гражданское право, представительство, приничиал, агент, третьи лица, права, обязанности, Россия, США.

Abstract: This article is dedicated to the question of mutual rights and obligations of the representative and third parties, as well as the represented and third parties within the framework of legal relations of the representation in Russian and American legal systems. The author conducts a comparative analysis of the legal relations of the representation within Russian and American legal systems on the example of legal regulation of mutual rights of the main parties of legal relations with third parties. The author also examines issues such as: emergence of mutual rights and obligations between the represented and third parties; informing third parties by the represented party; right (obligation) of the representative to enter into relations with third parties and the circle of his authority; limitation of rights of the representative to enter into relations with third parties for the purposes of acting in their interests. It is substantiated that the legal relations of the representation, as well as their legal regulation within Russian and American laws are rather similar. It is confirmed by the possibility of highlighting principles that are in common in both laws and the elements of these legal relations, the main of which are the rights and obligations of third parties in their cooperation with the main parties to legal relations of the representation.

Keywords: USA, Russia, Obligations, Rights, Third party, Agent, Principal, Representation, Civil law, Jurisprudence.

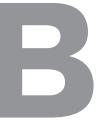

науке существует понимание природы представительства как двустороннего договорного отношения между агентом и принципалом[1]. Напомним, что несмотря на тот факт, что договор представительства является двусторонним, само правоотношение направлено на создание взаимных прав и обязанностей агента и принципала с третьими лицами, а также на осуществление действий в отношении послед- них. Таким образом, несмотря на существование множественности доктринальных подходов к пониманию сущности данного правоотношения (как двустороннее или как трёхстороннее)[2], само предназначение данного правоотношения предполагает создание как взаимных прав и обязанностей в отношениях представителя с третьими лицами, так и наличие правового регулирования отношений между представляемым и третьими лицами. 
Как следствие, определение данного правоотношения лишь как двустороннего, является ограниченным и не полностью отражает его сущность. Более того, такой подход не соответствует и позитивному праву, в котором устанавливается альтернатива образования взаимных прав и обязанностей трех, а не двух субъектов. Действительно, правовое регулирование агентского договора однозначно предусматривает - помимо очевидно существующих двусторонних договорных отношений между принципалом и агентом - возможность создания взаимных прав и обязанностей как между принципалом и третьим лицом (абз. 1 п.1 ст. 1005 ГК РФ), так и между агентом и третьим лицами (абз. 2 п.1 ст. 1005 ГК РФ). Как следствие, рассмотрение вопроса о взаимных правах и обязанностях, возникающих между агентом и третьими лицами является неотъемлемой частью такого сложного трехстороннего правоотношения.

\section{1. Взаимные права и обязанности представляемого лица и третьих лиц}

На первый взгляд, правоотношение представительства предполагает, что права и обязанности здесь возникают лишь между представителем и представляемым им лицом; как следствие, другие отношения (в частности отношения указанных субъектов с третьими лицами), на первый взгляд, имеют лишь второстепенное значение. В тоже время, основным объектом правоотношения представительства, или целью, для которой оно образуется, является именно создание взаимных прав и обязанностей между представляемым лицом и третьими лицами. В свою очередь, созданные таким образом права и обязанности представляемого лица и третьих лиц являются, практически, единственной формой взаимодействия представляемого лица и третьих лиц в рамках данного правоотношения; основное взаимодействие в рамках правоотношения представительства организуется между представляемым и представителем, с одной стороны, и представителем и третьими лицами, с другой стороны. Действительно, правоотношение представительства, по природе своей, предполагает невозможность или нежелание самого субъекта (представляемого) вступать в прямые отношения с третьими лицами. Как следствие, правовое регулирование представительства практически не содержит каких-либо уточнений по поводу взаимодействия представляемого лица и третьих лиц, ограничиваясь лишь определением итогов право- отношения представительства, заключающихся в определении взаимных прав и обязанностей представляемого и третьих лиц.

- возникновение взаимных прав и обязанностей у представляемого лиияа и третьих лии

В российском гражданском праве подход к вопросу возникновения взаимных прав и обязанностей в рамках правоотношения представительства неоднозначен. Так, например, по договору поручительства «права и обязанности по сделке, совершенной поверенным, возникают непосредственно у доверителя» (ст. 971 ГК РФ), т.е. представляемого. В рамках правового регулирования договора комиссии предусматривается противоположное решение: «по сделке, совершенной комиссионером с третьим лицом, приобретает права и становится обязанным комиссионер» (ст. 990 ГК РФ), т.е. представитель. Неоднозначна лишь ситуация с договором агентирования, где законодатель предусмотрел оба указанных варианта: по сделке, совершенной агентом с третьим лицом от своего имени и за счет принципала, приобретает права и становится обязанным агент, (...); По сделке, совершенной агентом с третьим лицом от имени и за счет принципала, права и обязанности возникают непосредственно у принципала" (ст. 1005 ГК РФ).

В тоже время, по данному вопросу, в судебной практике дело обстоит не так однозначно. Действительно, помимо договора агентирования, вопрос о безусловности обязанности представляемого лица нести ответственность за действия представителя возник и в одном из дел, рассматриваемых Верховным Судом РФ [3], касающегося договора поручения. В рамках данного дела доверитель выполнил обязанности по отгрузке товара, тогда как третье лицо не оплатило поставленный товар. Суд пришел к выводу о том, что поверенный должен нести перед доверителем ответственность за неоплату третьим лицом товара, поскольку он не обеспечил своевременного получения от третьего лица причитающихся с него платежей. Таким образом, несмотря на принцип возникновения прав и обязанностей лишь между представляемым лицом третьими лицами, с целью защиты прав представляемого лица, их обеспечение происходит посредством ответственности представителя, что несколько искажает указанный принцип.

В американском праве подход аналогичен. Иначе говоря, здесь также существует принцип, в соответствии с которым права и обязанности по сделкам совершенным в рамках правоотношения 
представительства несет принципал; взаимные права и обязанности возникают между ним и третьим лицом. Более того, вопрос наличия или отсутствия полномочий у агента здесь также является вопросом ответственности последнего. Действительно, если агент не имел полномочия на совершение сделки от имени представляемого лица с третьими лицами, то он может быть призван к ответственности. В тоже время обязанным субъектом по сделкам все равно остается представляемое лицо, вне зависимости от того, имел ли агент полномочие на заключение такой сделки [4], что свидетельствует, еще раз, о фидуциарной природе данного правоотношения.

В американском праве ответственность принципала по сделкам, заключённым агентом с третьими лицами, практически, безусловна; исключением являются лишь случаи нарушения агентом сферы вменённых ему полномочий. Иначе говоря, практически во всех случаях принципал будет связан обязанностями и наделен правами в отношении третьих лиц, по сделкам заключенным агентом в его интересах с третьими лицами, действующим в рамках вмененных ему представляемым лицом полномочий. Причем, в американском праве принципал будет обязанным даже тогда, когда агент действует от имени, так называемого, неразглашенного (undisclosed) принципала, т.e. когда третье лицо даже не предполагает, что оно взаимодействует с агентом (the third party has no notice that the agent is acting for a principal $(\S 1.04$ (Terminology) Свода правил представительства)). Здесь стоит обратить внимание на небольшое различие с российским законодательством в ситуации, когда агент, взаимодействуя с третьим лицом от своего имени - т.е. когда третье лицо не предполагает, что оно взаимодействует с агентом, а имеет все основания полагать что речь идет о настоящем контрагенте по сделке - приобретает права и обязанности сам агент. Действительно, здесь ситуация аналогична агентскому правоотношению с неразглашенным принципалом по американскому праву, но в отличие от последнего, в российском праве ответственность по таким сделкам будет нести агент, а не принципал. Такой подход, на наш взгляд, следует объяснить большей озабоченностью российского законодателя о создании различных гарантий по защите прав принципала и третьих лиц. Тем не менее, каким бы ни было объяснение такого различия между российским и американским правом, очевидно, что в российском праве принцип ответственности представляемого лица по совершенным агентом сделкам имеет свои исключения, тогда как в американском праве он практически безусловен: в рамках американского права, права и обязанности по сделкам совершенным агентом создаются только в лице принципала и третьих лиц. Как следствие, можно утверждать, что по данному признаку американское право не знает аналога российского правоотношения комиссии или агентирования, в котором агент совершает сделку от своего имени.

- информирование третьих лиц представляемым лицьом

Как мы уже отметили, за исключением прав и обязанностей, созданных в рамках юридических действий, совершенных агентом на основании договора представительства, каких-либо других прав и обязанностей принципала по отношению к третьим лицам и vice versa не предусмотрено. Действительно, в рамках данного правоотношения взаимодействуют принципал и агент, с одной стороны, а также агент и третьи лица, с другой стороны, тогда как принципал и третьи лица не вступают в непосредственные отношения и не наделены для данных целей какими-либо правами и обязанностями. Тем не менее, американское гражданское право предусматривает возможность взаимодействия принципала с третьим лицом в рамках правоотношения представительства. Речь идет о взаимном обмене информацией между принципалом и третьим лицом.

Во-первых, это касается ситуации, когда создаются, так называемые, видимые полномочия (Apparent authority) агента [5]. В соответствии со Сводом правил по представительству (§ 2.03), видимые полномочия возникают у агента «когда третья сторона разумно полагаясь на волеизъявление принципала считает, что то или иное лицо является его агентом» (when a third party reasonably believes the actor has authority to act on behalf of the principal and that belief is traceable to the principal's manifestations). Иначе говоря, принципал может создать агентское правоотношение, выразив свою волю соответствующим образом напрямую третьему лицу.

Во-вторых, речь идет об информировании третьим лицом принципала (notification), которое является очень важным институтом американского права агентирования. Действительно, американский Свод правил по представительству посвятил данному вопросу целую главу (Chapter 5. "Notifications And Notice"). В соответствии с 
принципом информирования считается, что принципал был проинформирован третьим лицом, в случае если он проинформировал агента (§ 5.02 "Notification Given By Or To An Agent"). Следствием такой презумпции информирования принципала третьим лицом, посредством передачи информации агенту, станет возможность использования данной презумпции против принципала (за исключением случаев, когда агент действовал в собственных интересах, противоречащих интересам принципала [6]).

В последнем случае, мы, еще раз, можем наблюдать проявление фидуциарного характера правоотношения представительства, так как презюмируется, что действия совершённые третьим лицом в отношении агента, совершены в отношении принципала: такое вменение предполагает наличие доверительных отношений между агентом и принципалом.

Стоит напомнить, что подобного обязательства в общем регулировании правоотношений представительства мы не обнаружим. В тоже время особенности отдельных видов правоотношений представительства привели к необходимости установления обязанности представляемого лица предоставлять соответствующую информацию третьим лицам. Так, например, в туристской сфере установлена «..ответственность туроператора и турагента, а также ответственность каждой из сторон перед туристом и (или) иным заказчиком за непредставление или представление недостоверной информации ..» (Ст. 9 Федеральный закон от 24 ноября 1996 года № 132-Ф3 «Об основах туристской деятельности в Российской Федерации»//Собрание законодательства Российской Федерации, 1996, № 49, ст. 5491).

\section{2. Взаимные права и обязанности представителя и третьих лиц}

- право представителя вступать в отношения с третьими лицами и круг его полномочий

Как мы уже отметили, агент обязан вступать в отношения с третьими лицами от имени представляемого лица за исключением отдельных случаев: правоотношения поручения и его американского эквивалента - безвозмездного агентирования, где такая обязанность либо сведена к минимуму, либо вообще отсутствует. Коррелятивно, у принципала существует право требовать от представителя вступать в такие отношения. Тем не менее, не все так просто, так как создание прав и обязанностей между принципалом и третьими лицами, посредством действий агента, содержит множество сложностей, большая часть из которых касается определения полномочий агента. В рамках отношений агента с третьими лицами, определение полномочий агента имеет важное значение, так как от того располагает ли представитель полномочием на представительство будет зависеть возможность агента осуществлять сделки с третьими лицами, а также (в случае отсутствия такого полномочия) нести ответственность по совершенной сделке.

Итак, для того чтобы агент мог вступать в отношения с третьими лицами от имени представляемого лица, т.е. располагал правом на совершение действий от имени представляемого, последнее должно наделить агента полномочиями. Если в российском праве данному вопросу уделяется меньшее внимание в связи, на наш взгляд, с общеправовой необходимостью обязанности письменной формы для сделок (в том числе и договоров представительства) между юридическими лицами и последними и гражданами (ст. 161 ГК РФ), что позволяет довольно чётко определить права и обязанности представителя, то в американском праве данному вопросу уделено больше внимания. В американском праве существует несколько способов наделения агента правом представлять принципала. Все они определены в рамках Свода правил по представительству (См. гл. 2 «Принципы предоставления полномочий» (Principles of Attribution). Среди них: действительное полномочие на представление (Actual authority); видимое полномочие (Apparent authority); отношения работника и работодателя (Respondeat superior); эстоппель (Estopppel); неотъемлемое право представительства (Inherent Agency power); ратификация права на представительство (Ratification) [7].

Действительное полномочие агента определяется $\S 2.02$ Свода правил по представительству как полномочие агента, которое, к моменту осуществления действий в отношении третьих лиц, позволяло агенту разумно полагать, что сам принципал желает совершения агентом соответствующих действий, т.е. действительным полномочием агента является полномочие которое ему было действительно передано самим принципалом. Стоит отметить, что Свод правил представительства также дольно подробно описывает каким образом должен определяться объем полномочий агента и, как следствие, как должен определяться объем тех действий которые агент может осуществить в отношении третьего лица (§ 2.02). Так, помимо 
тех действий которые принципал ясно (expressly) разрешил агенту осуществлять в отношении третьих лиц, Свод правил представительства уточнил ряд принципов в соответствии с которыми такие полномочия агента в отношении третьих лиц могут быть предполагаемыми (implied). Чаще всего речь идет о полномочиях агента, которые необходимы для реализации целей представительства. Как следствие, агент наделяется полномочием разумной (reasonable) интерпретации (interpretation) желаний принципала. Так, например, назначение председателя совета директоров, предполагает наделение его правом подписывать чеки от имени компании; наделение брокера по недвижимости правом ее продажи предполагает полномочие агента по подписанию соответствующих, необходимых для реализации данной сделки, документов и т.п.

В судебной практике возникло множество проблем определения полномочий агента. Так, если в том что касается действий которые принципал разрешил агенту выполнять ясно (expressly) особых проблем мы не обнаружим, то, так называемые, предполагаемые (implied) полномочия агента потребовали довольно подробного уточнения в судебной практике. Данная проблема возникла на практике в связи с особой природой договора представительства, которая, как мы уже отметили, заключается в невозможности определения в договоре представительства достижения агентом конкретного результата (например обязательство агента-адвоката выиграть судебный процесс не существует), а лишь о выполнении предусмотренных договором действий, направленных на достижение того или иного результата. Такое отличие договора представительства от, например, договора подряда, где речь идет об «определенной работе» (ст. 702 ГК РФ), на практике привело к многочисленным проблемам определения действительных полномочий агента. Так, например, в рамках договора коммерческого представительства, полномочия агента могут быть очерчены довольно абстрактно и заключаться в продаже или покупке того или иного товара. Более того, в американской науке гражданского права [8] признается, что полномочия агента могут быть определены даже молчанием принципала (при условии, что он был информирован), или, точнее, отсутствием возражения с его стороны. Аналогичным образом, осуществляется определение полномочий агента в случае срочности (emergency), которые также могут предполагаться: в случае если агент не может известить принципала во время, а ситуация тре- бует от агента предпринять какие-либо действия в отношении третьих лиц, то в данном случае также подразумевается, что агент располагал правом на осуществление таких действий.

Как следствие, во всех этих случаях агент создаст своими действиями взаимные права и обязанности между принципалом и третьим лицом, причем вне зависимости был ли известен третьей стороне фактический круг полномочий агента и, вообще, является ли агент чьим-либо агентом. В данных ситуациях идет речь о том, что агент может действовать даже в интересах неразглашенного (или частично разглашенного) третьему лицу принципала (totally undisclosed and partially disclosed principal)[9]. Таким образом, в случаях когда агент был наделен принципалом правом на осуществление представительства он располагает правом предоставить третьему лицу права и наложить на него обязанности от имени принципала вне зависимости от того знает ли последний о том, что агент действует в качестве агента.

Видимые полномочия (Apparent authority) агента возникают когда третье лицо может разумно полагать, что агент был наделен принципалом правом на осуществление действий. В отличие от действительного полномочия, право агента действовать в данном случае возникает не в связи с заключением договора представляемого лица с агентом, а в связи с тем, что у третьего лица создалось впечатление, что агент действительно им наделён. Конкретно, предполагаемое полномочие агента возникает в тех случаях, когда принципал дал понять третьему лицу, что агент располагает полномочием на осуществление действий в его интересах; такие полномочия «(...)существуют лишь в представлении третьего лица и в содержание реально существующего правоотношения между принципалом и агентом не входят» [10]. Иначе говоря, по определению $\S 2.03$ Свода правил по представительству «видимое полномочие (возникает) когда, в связи с действиями самого принципала, третья сторона может разумно полагать, что агент наделен полномочиями по осуществлению действий в интересах принципала».

Такая особенность, помимо определения ответственного по совершенной сделке лица, имеет существенное значение для отношений агента и третьего лица, так как в таких случаях агент может располагать правом на осуществление действий, которые изначально агенту не предполагалось осуществлять, т.е. выходить за пределы действительных полномочий, переданных агенту принци- 
палом (т.е. которыми он вообще не располагал). На практике, данная теория нацелена на защиту прав третьих лиц. В качестве наиболее частого примера видимого полномочия агента в американской науке гражданского права [4] используется пример самозванца, который переодевшись в униформу продавца и проникнув на территорию магазина, выписывал покупателям чеки и получал от них наличные денежные средства. В данном случае суды рассматривали отношения продавца-самозванца и покупателей как отношения агента (продавца) и третьих лиц, возложив, как следствие, ответственность по данным сделкам на принципала (магазин), так как тот факт, что продавец-самозванец находился на территории магазина (принципала) и был переодет в униформу магазина позволил третьему лицу разумно предполагать что данный продавецсамозванец является агентом принципала [11].

Последний пример иногда выделяется в науке в отдельную категорию способов наделения агента правом на осуществление действий в отношении третьего лица и называется эстоппелем. Стоит отметить, что выделение в рамках, так называемого, видимого полномочия агента отдельной категории эстоппеля является довольно спорным, несмотря на тот факт, что Свод правил по представительству выделяет данный способ наделения агента правом на осуществление действий в отношении третьих лиц в отдельную категорию и посвящает ему отдельную статью (§ 2.05 Estoppel To Deny Existence Of Agency Relationship). Так, в американской науке гражданского права отмечается, что «в большинстве случаев видимого полномочия будет присутствовать эстоппель» [4], а «отличие видимого полномочия от эстоппеля является лишь академической (научной) разработкой, не имеющей значения на практике» [9]. Действительно, между видимым полномочием и эстопплем практически невозможно обнаружить отличия, так как в обоих случаях у третьего лица возникает разумное основание полагать, что агент наделен полномочием по представлению принципала; т.е., что такое третье лицо может смело вступать с таким агентом в отношения. Единственное отличие эстоппеля от видимого полномочия заключается в том, что в рамках эстоппеля принципал дает понять третьему лицу, что другое лицо является его представителем не явным образом - как в рамках, собственно, видимых полномочий - a, напротив, такая видимость создается в результате небрежности со стороны принципала. Иначе говоря, у агента возникает полномочие на представление не в связи с тем, что принципал информировал третье лицо о том, что то или иное другое лицо является агентом, а в связи с тем, что он не информировал третье лицо о том, что то или иное лицо не является агентом. Таким образом, здесь речь просто-напросто идет об одном из способов определения деликтной ответственности принципала, который будет нести ответственность по сделкам заключенным агентом, который де-факто не имел полномочия на их заключение.

Еще одним способом определения того, располагает ли агент правом на представление интересов принципала в сделках с третьими лицами в американском праве является, так называемое, неотьемлемое право представительства (Inherent Agency Power). Такое полномочие агента служит еще большему расширению ответственности принципала по сделкам, чем действительные и видимые полномочия (даже эстоппель). Действительно, в соответствии с данной теорией агент может наложить на принципала обязательства ввиду очень широкого круга полномочий, который чаще всего ассоциируется в американской науке гражданского права с общим агентством (general agency) [12].

Данное полномочие представителя, как и предыдущие, было создано судебной практикой с целью защитить права третьих лиц в ситуациях, когда агент, действуя вопреки желаниям принципала, нанес ущерб добросовестно действующим третьим лицам. Тем не менее, оно применяется только к агентам с, так называемыми, общими полномочиями, т.е. к тем представителям, которые наделены принципалом абстрактными полномочиями и действуют как агенты на постоянной основе. Как следствие, ответственность принципала в таких случаях расширена в связи с тем, что он наделил агента широкими и довольно абстрактно определенными полномочиями.

В тоже время, в американской науке гражданского права отмечается, что судебная практика не соответствует доктринальному выделению агента с общими полномочиями из категории агента с видимыми полномочиями. Действительно, различия в полномочиях между агентом с общими полномочиями и агентом с видимыми полномочиями нельзя признать серьезной. Выделение агента с общими полномочиями в американском праве стало необходимым лишь для ситуаций с неразглашенными (undisclosed) принципалами, так как в таких ситуациях - по определению - у агента не существует видимых полномочий: как следствие, в таких ситуациях за ним могут быть признаны 
только полномочия общего агента (или неотъемлемые права представительства), которые по природе своей практически идентичны видимым. Скорее всего, именно по этой причине сходства видимых полномочий агента с неотъемлемыми, последние не были выделены в рамках Свода правил по представительству в отдельную категорию.

Очевидно, что во всех упомянутых выше способах определения полномочий агента (действительных, видимых (эстоппеля), неотъемлемых) признается, что право агента на вступление в отношения с третьими лицами от имени принципала существовало у него на момент совершения соответствующих действий в отношении третьих лиц. В соответствии с еще одной возможностью наделения агента правом на вступление в отношения с третьими лицами от имени принципала, данное право может у него появиться уже после совершения таких действий. В данном случае речь идет о наделении агента полномочиями постфактум, то есть посредством ратификации. Таким образом, какое либо лицо может действовать в качестве агента в отсутствии соответствующих на то полномочий и получить их последующим актом ратификации, т.е. последующим признанием принципалом совершения сделки агентом в его интересах.

Данный вид наделения агента полномочиями очень подробно урегулирован Сводом правил по представительству (глава 4), что придает ему высокое значение. Действительно, даже если не принимать во внимание многочисленную судебную практику, касающуюся ратификации полномочий агента (условий ее действительности (NAACP vs. Overstreet, 142 S.E. 2d 816 (GA 1965)); масштабов ратификации действий агента (Andrews vs. Claiborne Parish School Board, 189 So. 355 (La. 1939)); обязательств информирования принципала (Tempelton Construction Co. Vs. Kelly, 296 A2d 242 (Vt. 1972)) и т.п.), объем правового регулирования ратификации в американском праве агентирования дольно широк и состоит из восьми статей (§§ 4.01 - 4.08 Свода правил представительства).

Принцип в соответствии с которым работодатель несет ответственность за действия работника не нуждается в каких-либо пояснениях. Очевидно, что презумпция ответственности работодателя за действия работника, осуществлённые последним в рамках его трудовой деятельности (§ 2.04 Свода правил представительства) предполагает существование правового регулирования отношений агента (работника) и принципала (работодателя). Как следствие, право агента на совершение действий в отношении третьих лиц от имени принципала, здесь, является производным от трудового договора.

В российском праве мы не обнаружим настолько подробного законодательного регулирования вопросов наделения агента правом на вступление в отношения с третьими лицами от имени представляемого лица. Иначе говоря, вопросы проверки полномочий представителя или оснований для создания его действиями прав и обязанностей посредством взаимодействия с третьими лицами здесь, на первый взгляд, урегулированы менее подробно. В тоже время российская судебная практика пестрит примерами уточнения отдельных аспектов определения полномочий агента в отношениях с третьими лицами (См. Постановление Президиума Высшего Арбитражного Суда Российской Федерации № 12470/08 от 25 февраля 2009 г.).

Общепризнано, что одним из оснований признания действий лица в чьих-либо интересах в качестве агента является прямое указание закона. Напомним, что в американской науке гражданского права [13] также существуют мнения о том, что полномочия у агента на осуществление действий в отношении третьих лиц могут возникнуть в отсутствии договора. В данных случаях, полномочие представителя на представление не требует, как совершения каких-либо действий самим представляемым лицом, так и наступления каких-либо событий для этого, а возникают без специального полномочия; в силу закона. Иначе говоря, право представителя на вступление в отношения с третьими лицами здесь возникает в отсутствии договорных отношений с последними. Множество примеров такого наделения представителя правом на вступление в отношения с третьими лицами от имени представляемого мы можем обнаружить в семейном праве и даже за пределами гражданского права (в рамках административного права).

Тем не менее, в большинстве случаев, в рамках гражданского права представительство основано именно на договорной основе. Помимо собственно договора, отношения представительства также организуются и на основе другого документа доверенности (см. например ст. 975, п.1 ГК РФ). Последняя в свою очередь является не только документом, в котором представляемое лицо ограничивает круг полномочий, которыми он наделяет представителя, но выступает и средством внешней легитимации представителя перед третьими лица- 
ми; как следствие, она делает полномочие представителя очевидным для соответствующего третьего лица или неопределенного круга третьих лиц.

В отличие от американской науки гражданского права, в российской науке гражданского права, в рамках исследований посвященных правоотношениям представительства, доверенности отводиться очень важное значение. Более того, в российской науке гражданского права данное значение доверенности для правоотношений представительства связано именно с легитимацией полномочий представителя в глазах третьих лиц [14]. Стоит отметить, что несмотря на отсутствие такого института в американском праве, отдельные аспекты возникновения полномочий представителя, которые мы описали выше могут свидетельствовать о наличии аналогичных инструментов и в американском праве. Действительно, такой вид наделения агента правом на осуществление действий в интересах принципала как видимые полномочия (см. выше) свидетельствует о том, что сам принципал (principal manifestation) позволяет третьему лицу понять (when a third party reasonably believes), что то или иное лицо действует в качестве агента от имени принципала (the actor has authority to act on behalf of the principal) (См. $\$ 2.02$ (Apparent Authority) американского Свода правил представительства). Иначе говоря, в американском праве, в связи с неприменением такого инструмента как доверенность в рамках агентских отношений, существуют механизмы информирования третьих лиц о том, является ли то или иное лицо агентом и - если является - какими правами оно наделено. Как следствие, механизм видимых полномочий служит в американском праве аналогичной российскому праву функции, а именно: легитимации власти агента и защите прав третьих лиц.

Несмотря на то, что правовое регулирование отношений представительства в российском праве предполагает в отдельных случаях наличие, как договора, так и доверенности, определить круг полномочий представителя - как и в американском праве - не всегда удается с достоверностью. Об этом свидетельствует ряд положений Гражданского кодекса РФ. Действительно, например, в рамках правового регулирования договора комиссии, предусматривается возможность отступления от указаний комитента (ст. 995 ГК РФ) если по обстоятельствам дела это необходимо в интересах комитента, и, даже «право отступать от его (комиссионера) указаний без предварительного запроса» в рамках коммерческого представитель- ства. Как следствие, в российском праве существует эквивалент, так называемых, подразумеваемых полномочий, или, точнее, подкатегории таковых «неотъемлемых прав представительства» (Inherent Agency Power), которые принадлежат в американском праве общим агентам (general agents), обладающим широким кругом полномочий. Иначе говоря, в российском праве у третьего лица также могут возникнуть сложности с определением того, наделен ли агент правом на представление и какими полномочиями он наделен.

В российском праве существует и аналог американской ратификации, в соответствии с которой агент может быть наделен полномочием постфактум. В рамках правового регулирования, все тех же, полномочий комиссионера, ГК РФ гласит «Если комиссионер купил имущество по цене выше согласованной с комитентом, комитент, не желающий принять такую покупку, обязан заявить об этом комиссионеру в разумный срок по получении от него извещения о заключении сделки с третьим лицом. В противном случае покупка признается принятой комитентом» (п. 3, ст. 995). Иначе говоря, как и в американском праве, представитель по российскому праву может действовать вне пределов вменных ему представляемым лицом в обязанность, полномочий, при условии, что уже после совершения сделки представляемое лицо ратифицирует (в данном случае посредством молчания) совершенную таким образом сделку (одобрение сделки представляемым лицом).

Вообще стоит отметить, что по данному вопросу правоотношение комиссии по российскому праву (а также агентирования в рамках которого сделки совершаются от имени агента) наиболее схоже с так называемым непоименованным агентированием (unidentified agency) по американскому праву, отличительной чертой которого является неосведомленность третьих лиц о том что они вступают отношения лишь с агентом и полагающих что они взаимодействуют с полноценным контрагентом по сделке. Аналогичность данных правоотношений по российскому и американскому праву заключается в их правовом регулировании (См. подробнее гл. 50 ГК РФ и $\S \S 2.06,6.03,6.05 \ldots$ американского Свода правил представительства). Так, например, как в американском, так и российском праве, в рамках таких отношений: права и обязанности по сделкам возникают (как правило) между агентом и третьими лицами, а не между принципалом и третьими лицами, как в большинстве правоотношений 
представительства; полномочия представителя здесь расширены и он может себе позволить отступить от указаний представляемого им лица; в свою очередь, основное бремя ответственности по сделкам в рамках этих правоотношений возложено именно на плечи агента и т.п.

Отметим, что существование аналогий между российским и американским правом в вопросе определения права представителя на вступление в отношения с третьими лицами, а также определения его полномочий при взаимодействии с третьими не должно удивлять. Как мы уже отметили, правоотношение представительства не предполагает совершения действий с заранее определенным результатом как, например, строительство определенного здания по договору подряда или передачи определенной вещи по договору куплипродажи и т.п. В рамках правоотношения представительства речь идет о совершении действий в интересах представляемого, которые могут быть определены в более или менее абстрактной форме. В свою очередь, их объем варьируется не только от воли субъектов правоотношения, но и в зависимости от вида правоотношения представительства или конкретных обстоятельств, а аналогичность их правового регулирования в американском и российском порядке объясняются общей целью: необходимостью защиты прав принципала и третьих лиц.

Как следствие, и в российской судебной практике мы можем наблюдать многочисленные споры о том, был ли представитель наделен тем или иным полномочием. Так, если судебная практика справедливо признает, что общая формулировка представительства интересов представляемого не достаточна (См., например: постановление Девятого арбитражного апелляционного суда от 10.09.2008 по делу № А-40-13331/08-134-81, постановление ФАС Северо-Кавказского округа от 12.02.2009 по делу № А53-6540/2008-С2-28), то как российское, так и американское позитивное право открыто признают невозможность исчерпывающего определения всех полномочий представителя.

- ограничение прав представителя на вступление в отношения с третьими лицами с изелью осуществления действий в их интересах

Данное ограничение существует как в российском, так и американском праве. Такое ограничение можно объяснить фидуциарным характером правоотношения агента и принципала, так как на нормативном уровне и в судебной практике такой запрет чаще всего объясняется запретом на создание конкурентной среды между представляемым и третьим лицом. Действительно, в таких случаях агент должен будет действовать в интересах обоих лиц (и представляемого и третьего лица), что, как следствие, может привести к конфликту интересов представляемых лиц. Как в российском, так и зарубежном праве, ограничение прав агента на вступление в отношения с третьими лицами с целью действий в их интересах чаще всего касается коммерческой деятельности, т.е. коммерческого представительства.

Так, в соответствии с $\S 8.03$ Свода правил по представительству закрепляется правило в соответствии с которым агент «обязуется не действовать от имени третьего лица в сделках, направленных на реализацию агентского правоотношения с принципалом» («(...)duty not to deal with the principal as or on behalf of an adverse party in a transaction connected with the agency relationship). Стоит отметить, что данное ограничение прав агента связано с обязанностью лояльного поведения представителя по отношению к представляемому лицу (см. выше 1.2.), т.е. объясняется фидуциарным характером правоотношения принципала и агента и распространяется не только на ограничение действий агента в интересах третьих лиц, но и на ограничение действий агента в собственных интересах.

Американское право в вопросе вступления агента в отношения с третьими лицами с целью осуществления действий в их интересах довольно подробно урегулировано. Так, для подержания фидуциарности в отношениях агента и принципала, здесь агенту также запрещается получать от третьих лиц какую-либо материальную выгоду, связанную со сделками которые ему поручено осуществлять в рамках правоотношения с принципалом ((...)agent has a duty not to acquire a material benefit from a third party in connection with transactions conducted (...) on behalf of the principal $(.)).(\S$ 8.02 Restatement of the Law of Agency).

Еще одним примером ограничения прав агента, с целью сохранения фидуциарного характера его отношений с принципалом, может служить прямой запрет на осуществление действий с третьими лицами-конкурентами принципала. Так, $\$ 8.04$ американского Свода правил по представительству запрещает агенту действовать в интересах и помогать конкурентам принципала ((..) agent has a duty to refrain from competing with the principal and taking action on behalf of or otherwise assisting the principal's competitors). 
В российском праве такое обязательство наиболее ярким образом выражено в рамках агентского договора. Действительно, п. 2 ст. 1007 ГК РФ гласит «Агентским договором может быть предусмотрено обязательство агента не заключать с другими принципалами аналогичных агентских договоров, которые должны исполняться на территории, полностью или частично совпадающей с территорией, указанной в договоре”.

- ограничение прав представителя на передоверие действий по исполнению обязательств третьим лииам

Данное ограничение, как и предыдущее, вызвано также фидуциарным характером правоотношения представителя и представляемого лица, но применяется довольно редко и ограничивается как в российском так и американском праве личностно-доверительных отношений представительства.

Действительно, данное ограничение прав представителя в российском праве не является однозначным и применяется в наиболее полном объеме лишь в рамках правоотношения поручения. Более того, данный вопрос в рамках этого правоотношения является настолько важным вопросом, что ему посвящена отдельная статья Гражданского кодекса: «Передоверие исполнения поручения» (ст. 976 ГК РФ). Действительно, передоверие исполнения действий представителем в рамках договора поручения возможно «лишь в случаях и на условиях предусмотренных ст. 187», а представляемое лицо, здесь, располагает правом на отвод заместителя поверенного (п. 2 ст. 976 ГК РФ). Такой подход в данному вопросу не удивляет, так как правоотношение поручения носит наиболее ярко выраженный (по сравнению с другими правоотношениями представительства в российском праве) фидуциарный характер, что проявляется здесь в таких особенностях как: необходимость личного исполнения поручения (ст. 974 ГК РФ); возможность одностороннего прекращения данного правоотношения (п. 2, ст. 977 ГК РФ); возможность безвозмездного предоставления услуг поручения (ст. 972 ГК РФ) и т.п.

Правило ограничения прав представителя на передоверие действий по обязательствам договора представительства третьим лицам очень мягко сформулировано в рамках правового регулирования договора комиссии. Более того, здесь передоверие (субкомиссия) возможно в любом случае, а его ограничение лишь может быть предусмотрено в самом договоре комиссии (ст. 994 ГК РФ). Аналогичен и подход законодателя к данному вопросу и в рамках правового регулирования договора агентирования (п. 1 ст. 1009 ГК РФ).

Принимая во внимание, что правоотношение представительства в американском праве, также как и в российском праве, носит фидуциарный характер, мы в нем также обнаружим подобные ограничения прав представителя на передоверие действий по исполнению обязательств третьим лицам. П. $2^{\text {ой }} \S 3.15$ американского Свода правил по представительству, посвященный субагентскому договору (Subagency), однозначно ограничивает право агента по передаче своих полномочий третьим лицам: «агент может назначить субагента только если агент располагает действительным или видимым полномочием на совершение данного действия» (An agent may appoint a subagent only if the agent has actual or apparent authority to do so).

\section{Библиография:}

1. Егоров А.В. Понятие о признаки посредничества в гражданском праве // Юрист. 2002. № 1. С. 23

2. Красавчиков О.А. Гражданские организационно-правовые отношения // Советское государство и право. 1966. № 10. C. 56.

3. Постановление Президиума ВАС РФ от 14.06.2001 № 6510/00 по делу № A40-1662/00-50-18

4. D.S. Kleinberger, Agency, Partnership, and LLC's (2nd ed. 2002), p. 20.

5. K.J. Haupt, D.L. Rockwell, Principles of California Real Estate, Rockwell Publishing, 2006. p. 162 ssq.

6. R.J. Conviser, Gilbert Law Summaries, Agency, Partnership, and Limited liability companies, 5th ed. 2003, p. 68, 69.

7. R. Munday, Agency: Law and Principles, Oxford University Press, 2010, p. 41 ssq.

8. D.S. Kleinberger, Agency, Partnership, and LLC's (2nd ed. 2002), p. 22

9. R.J. Conviser, Gilbert Law Summaries, Agency, Partnership, and Limited liability companies, 5th ed. 2003 , p. 28.

10. Субботин Н.А. Представительство в англо-американском праве. Дисс. к.ю.н. М., 1983. С. 120.

11. S.B. Presser, An introduction to the Law of Business Organizations. Cases, Notes and Questions. Third Edition. West. p. 28.

12. J.D. Hynes, Agency, Partnership and LLC (2001), 2nd ed. P. 138.

13. W. Bowstead, Law of Agency, The Lawbook Exchange, Ltd., 2006. p. 34.

14. Цвайгерт К., Кетц Х. Введение в сравнительное правоведение в сфере частного права. В 2-х т. Т. 2. М.: Международные отношения, 1998. С. 148. 
DOI: $10.7256 / 1811-9018.2016 .5 .19057$

При цитировании этой статьи сноска на doi обязательна

Юридический практикум

\section{References (transliterated):}

1. Egorov A.V. Ponyatie o priznaki posrednichestva v grazhdanskom prave // Yurist. 2002. № 1. S. 23

2. Krasavchikov O.A. Grazhdanskie organizatsionno-pravovye otnosheniya // Sovetskoe gosudarstvo i pravo. 1966. № 10. S. 56.

3. D.S. Kleinberger, Agency, Partnership, and LLC's (2nd ed. 2002), p. 20.

4. K.J. Haupt, D.L. Rockwell, Principles of California Real Estate, Rockwell Publishing, 2006. p. 162 ssq.

5. R.J. Conviser, Gilbert Law Summaries, Agency, Partnership, and Limited liability companies, 5th ed. 2003, r. 68, 69.

6. R. Munday, Agency: Law and Principles, Oxford University Press, 2010, p. 41 ssq.

7. D.S. Kleinberger, Agency, Partnership, and LLC's (2nd ed. 2002), p. 22

8. R.J. Conviser, Gilbert Law Summaries, Agency, Partnership, and Limited liability companies, 5th ed. 2003 , r. 28.

9. Subbotin N.A. Predstavitel'stvo v anglo-amerikanskom prave. Diss. k.yu.n. M., 1983. S. 120.

10. S.B. Presser, An introduction to the Law of Business Organizations. Cases, Notes and Questions. Third Edition. West. p. 28.

11. J.D. Hynes, Agency, Partnership and LLC (2001), 2nd ed. R. 138.

12. W. Bowstead, Law of Agency, The Lawbook Exchange, Ltd., 2006. p. 34.

13. Tsvaigert K., Ketts X. Vvedenie v sravnitel'noe pravovedenie v sfere chastnogo prava. V 2-kh t. T. 2. M.: Mezhdunarodnye otnosheniya, 1998. S. 148. 